P-ISSN 2580 - 7781

E-ISSN 2615 - 3238

\title{
STRATEGI OPTIMALISASI PENGGUNAAN LAHAN MARGINAL UNTUK PENGEMBANGAN KOMODITAS TANAMAN PANGAN
}

\section{MARGINAL LAND USE OPTIMIZATION STRATEGY FOR DEVELOPING FOOD PLANT COMMODITIES}

\author{
Sasmita Sari $^{1^{*}}$, Martono Achmar ${ }^{2}$ D. B. Zahrosa ${ }^{3}$ \\ ${ }^{1,2}$ Program Studi Agribisnis, Fakultas Pertanian, Universitas Abdurachman Saleh \\ ${ }^{3}$ Program Studi Agribisnis, Fakultas Pertanian, Universitas Jember \\ Email : 'biantaka13@gmail.com
}

\begin{abstract}
ABSTRAK
Tujuan penelitian adalah menyusun strategi optimalisasi penggunaan lahan marginal dalam mengembangkan komoditas tanaman pangan. Daerah penelitian yaitu di Kabupaten Situbondo dengan fokus penelitian di Kecamatan Sumbermalang dan Kecamatan Jatibanteng karena kedua wilayah tersebut didominasi lahan kering dan lahan marginal. Metode penelitian menggunakan pendekatan deskriptif. Metode pengambilan data primer dan sekunder. Pengambilan sampel yang dilakukan secara sengaja dan Insidental Sampilng. Metode analisis menggunakan Force Field Analysis (FFA). Hasil penelitian menunjukkan bahwa teridentifikasi faktor pendorong yaitu lahan untuk usahatani tersedia, terdapat program pengembangan lahan marginal, petani mempunyai pengalaman berusahatani yang relatif lama, pemeliharaan ternak, terdapat tenaga penyuluh pertanian, diversifikasi tanaman, dukungan sosio budaya setempat. Sedangkan faktor penghambat terbatasnya akses terhadap lembaga keuangan, terbatasnya sarana transportasi, kurang mendukungnya infrastruktur pertanian, rendahnya aplikasi teknologi, sepanjang tahun air tidak tersedia dengan cukup, sangat miskin unsur hara dan rendahnya bahan organik dan banyak lahan yang tidak digunakan lebih dari 2 tahun. Pendekatan ekosistem melalui perbaikan kesuburan tanah dan pemilihan berbagai jenis tanaman pangan yang sesuai dan menguntungkan serta usaha peternakan ini merupakan strategi yang tepat dalam optimalisasi penggunaan lahan marginal untuk pengembangan komoditas tanaman pangan.
\end{abstract}

Kata Kunci: Lahan Marjinal, Strategi dan Force Field Analysis (FFA)

\begin{abstract}
ABSTRACK
The research objective was to develop strategies for optimizing marginal land use in developing food crop commodities. The research area is Situbondo District with the focus of research in the Sumbermalang and Jatibanteng Districts because these two areas are dominated by dry land and marginal land. The research method uses a descriptive approach. Primary and secondary data collection methods. Intentional sampling and incidental Sampilng. The analysis method uses Force Field Analysis (FFA). The results showed that the driving factors identified were available land for farming, marginal land development programs, farmers had relatively long farming experience, livestock raising, agricultural extension workers, plant diversification, and local socio-cultural support. Meanwhile, the inhibiting factors are limited access to financial institutions, limited means of transportation, inadequate agricultural infrastructure, low technology application, insufficient water throughout the year, very poor nutrients and low organic matter and a lot of land that has not been used for more than 2 years. The ecosystem approach through improving soil fertility and selecting various types of suitable and
\end{abstract}


P-ISSN $2580-7781$

E-ISSN 2615 - 3238

profitable food plants and livestock business is the right strategy in optimizing the use of marginal land for the development of food crop commodities

Keyword: Lahan marginal, strategi dan Force Field Analysis (FFA)

\section{PENDAHULUAN}

Kabupaten Situbondo sebagai salah satu wilayah Provinsi Jawa Timur yang memiliki dataran tinggi dengan variasi topografi antara datar, bergelombang dan berbukit serta dikelilingi oleh pegunungan Ijen, Raung dan Argopuro, pada kenyataannya telah memberikan bukti sebagai potensi alam yang dapat dimanfaatkan secara optimal melalui pengembangan komoditas unggulan tanaman pangan. Menurut data dari (BPS tahun 2019), Kabupaten Situbondo memiliki luas $1.638,50 \mathrm{Km}^{2}$ atau $163.850 \mathrm{Ha}$, berdasarkan atas distribusi penggunaan lahan pertanian tahun 2017 terdiri dari lahan sawah seluas $33.887 \mathrm{Ha}$ dan lahan bukan sawah seluas 32.074 Ha.

Tanah mempunyai peranan penting terhadap pertumbuhan tanaman dan produksi tanaman. Dalam budidaya tanaman pangan, tanah mempunyai fungsi sebagai penyedia unsur hara dan air. Unsur hara dan air yang ada dalam tanah ini dapat menurun, bahkan dapat menghilang. Hilangnya fungsi inilah yang menyebabkan produkvitas tanah tidak optimal untuk kebutuhan pertumbuhan tanaman dan menjadi tanah marginal. Jika tanah ini diusahakan untuk budidaya tanaman, maka akan memerlukan teknologi yang tepat, sehingga menambah biaya pada usahatani. Selain itu, tanah ini juga tidak mempunyai fungsi ekologis yang baik terhadap lingkungan.

Dalam rangka pemuasan kebutuhan dan keinginan masyarakat yang terus menerus berkembang, pengelolaan sumberdaya lahan seringkali kurang maksimal dan tidak mempertimbangkan aspek keberlanjutannya sehingga kelestarian lingkungan semakin terancam. Akibatnya, sumberdaya lahan yang memiliki kualitas kesuburan tinggi menjadi kurang dan masyarakat semakin bergantung pada sumberdaya lahan yang marginal. Dengan demikian, secara keseluruhan aktifitas kehidupan masayarakat lebih condong pada sistem pemanfaatan sumberdaya lahan dengan daya dukung yang menurun. 
P-ISSN $2580-7781$

E-ISSN 2615 - 3238

Lahan marginal merupakan lahan kering yang memiliki kandungan hara terbatas. Pada usahatani lahan marginal, bila ditanami dengan tanaman semusim, produktivitas relatif rendah serta mengalami permasalahan sosial ekonomi seperti tekanan penduduk yang terus meningkat dan masalah biofisik. Sehubungan dengan hal tersebut kerjasama antara pemerintah, masyarakat, dan investor perlu dibangun guna meningkatkan kualitas dan kuantitas sumberdaya yang dimiliki. Oleh karena itu, tujuan dari penelitian ini adalah menyusun strategi optimalisasi penggunaan lahan marginal dalam mengembangkan komoditas tanaman pangan.

\section{METODE PENELITIAN}

Daerah penelitian ditentukan secara sengaja purposive method (Nazir, M. 2013) yaitu di Kabupaten Situbondo dengan fokus penelitian di Kecamatan Sumbermalang dan Kecamatan Jatibanteng karena kedua wilayah tersebut didominasi lahan kering dan marginal. Metode penelitian menggunakan pendekatan deskriptif. Metode pengambilan data primer dan sekunder. Pengambilan sampel yang dilakukan secara sengaja dan Insidental Sampling yaitu penentuan sampel berdasarkan kebetulan bertemu dengan peneliti (Soetriono dan Hanafie, 2017). Pada kegiatan penelitian ini, siapa saja yang secara kebetulan atau insidental bertemu dengan peneliti dapat digunakan sebagai sampel, bila dipandang orang yang kebetulan ditemui itu cocok sebagai sumber data. Metode analisis data menggunakan analisis Force Field Analysis (FFA) untuk mengetahui faktor pendorong dan penghambat optimalilasi penggunaan lahan marginal guna mendukung pengembangan komoditas tanaman pangan di Kabupaten Situbondo. Penentuan faktor pendorong dan penghambat tersebut diperoleh dari hasil wawancara dengan petani dan expert kemudian dianalisis menggunakan analisis FFA.

\section{HASIL DAN PEMBAHASAN}

\section{Faktor Pendorong dan Penghambat Optimalisasi Penggunaan Lahan Marginal}

Kabupaten Situbondo merupakan kabupaten agraris yang terletak di Propinsi Jawa Timur. Sebagai daerah agraris maka mata pencaharian utama 
P-ISSN $2580-7781$

E-ISSN 2615 - 3238

penduduknya adalah sektor pertanian. Pembangunan sektor pertanian terutama diarahkan untuk memenuhi kebutuhan masyarakat, karena keanekaragaman sumber pangan yang ada. Pertanian lahan kering yaitu areal pertanian yang tidak pernah di airi yang ditanami dengan jenis tanaman umur pendek saja. Berbagai jenis tanaman yang sesuai untuk dikembangkan pada lahan pertanian kering, baik tanaman pangan, hortikultura maupun perkebunan, termasuk usaha peternakan.

Berdasarkan analisis situasi, maka diperoleh beberapa faktor pendorong dan faktor penghambat dalam optimalilasi penggunaan lahan marginal guna mendukung pengembangan komoditas tanaman pangan di Kabupaten Situbondo, yaitu seperti yang tertera pada tabel 1 .

Tabel 1. Faktor Pendorong dan Faktor Penghambat Optimalilasi Penggunaan Lahan Marginal

\begin{tabular}{|c|c|c|c|}
\hline No & Faktor Pendorong & No & Faktor Penghambat \\
\hline D1 & Lahan untuk usahatani tersedia & H1 & $\begin{array}{l}\text { Terbatasnya akses terhadap lembaga } \\
\text { keuangan }\end{array}$ \\
\hline D2 & $\begin{array}{l}\text { Terdapat program pengembangan } \\
\text { lahan marginal }\end{array}$ & H2 & Terbatasnya sarana transportasi \\
\hline D3 & $\begin{array}{l}\text { Petani mempunyai pengalaman } \\
\text { berusahatani yang relatif lama }\end{array}$ & H3 & $\begin{array}{l}\text { Kurang mendukungnya infrastruktur } \\
\text { pertanian }\end{array}$ \\
\hline D4 & Pemeliharaan ternak & H4 & Rendanya aplikasi teknologi \\
\hline D5 & Terdapat tenaga penyuluh pertanian & H5 & $\begin{array}{l}\text { Sepanjang tahun air tidak tersedia } \\
\text { dengan cukup }\end{array}$ \\
\hline D6 & Diversifikasi tanaman & H6 & $\begin{array}{l}\text { Sangat miskin unsur hara dan } \\
\text { rendahnya bahan organik }\end{array}$ \\
\hline D7 & Dukungan sosio budaya setempat & H7 & $\begin{array}{l}\text { Banyak lahan yang tidak digunakan } \\
\text { lebih dari } 2 \text { tahun }\end{array}$ \\
\hline
\end{tabular}

\section{Strategi Optimalisasi Penggunaan Lahan Marginal dalam Mengembangkan Komoditas Tanaman Pangan}

Berdasarkan hasil analisa FFA mengenai penilaian faktor pendorong dan faktor penghambat seperti pada Tabel evaluasi faktor pendorong dan Tabel evaluasi faktor penghambat, maka dapat diketahui nilai dari Total Nilai Bobot (TNB) masing-masing faktor. Berdasarkan nilai TNB tersebut maka dapat ditentukan Faktor Kunci Keberhasilan (FKK) pada optimalilasi penggunaan lahan marginal guna mendukung pengembangan komoditas tanaman pangan di Kabupaten Situbondo yaitu dengan melihat nilai TNB yang terbesar. FKK disini 
P-ISSN $2580-7781$

E-ISSN 2615 - 3238

terbagi menjadi dua, yaitu FKK pendorong dan FKK penghambat seperti yang tertera pada tabel 2 dan tabel 3 .

Tabel 2. Evaluasi Faktor Pendorong Optimalilasi Penggunaan Lahan Marginal

\begin{tabular}{llccccccc}
\hline No & \multicolumn{1}{c}{ Faktor Pendorong } & BF & ND & NRK & NBD & NBK & TNB & FKK \\
\hline D1 & Lahan untuk usahatani tersedia & 0.17 & 4 & 2.92 & 0.67 & 0.49 & 1.15 & $1^{*}$ \\
D2 & $\begin{array}{l}\text { Terdapat program } \\
\text { pengembangan lahan marginal } \\
\text { Petani mempunyai pengalaman }\end{array}$ & 0.13 & 3 & 2.92 & 0.38 & 0.36 & 0.74 & \\
D3 & 3 & 3.00 & 0.50 & 0.50 & 1.00 & \\
& $\begin{array}{l}\text { berusahatani yang relatif lama } \\
\text { D4 }\end{array}$ & & & & & & & \\
D5 & Pemeliharaan ternak & 0.17 & 4 & 2.83 & 0.67 & 0.47 & 1.14 & \\
& $\begin{array}{l}\text { Terdapat tenaga penyuluh } \\
\text { pertanian }\end{array}$ & 0.13 & 2 & 2.08 & 0.25 & 0.26 & 0.51 & \\
D6 & $\begin{array}{l}\text { Diversifikasi tanaman } \\
\text { Dukungan sosio budaya }\end{array}$ & 0.08 & 2 & 2.42 & 0.17 & 0.20 & 0.37 & \\
D7 & 0.17 & 1 & 2.42 & 0.17 & 0.40 & 0.57 & \\
& setempat & & & & & & &
\end{tabular}

*): merupakan prioritas (FKK)

Keterangan:

BF : Bobot Faktor

ND : Nilai Dukungan

NRK : Nilai Rata-rata Keterkaitan

NBD : Nilai Bobot Dukungan

NBK : Nilai Bobot Keterkaitan

TNB : Total Nilai Bobot

FKK : Faktor Kunci Keberhasilan

Pada tabel 2 dapat diketahui FKK pendorong, yaitu faktor D1 (Tersedianya lahan untuk usahatani) dengan nilai urgensi sebesar 1,15. Wilayah Kabupaten Situbondo memiliki lahan pertanian (lahan kering) yang luas dan masih dapat dikembangkan dengan kondisi iklim yang mendukung untuk tumbuhnya berbagai jenis tanaman pertanian (pangan), perkebunan dan kehutanan yang bernilai ekonomis tinggi. Sebagian dari potensi sumberdaya lahan masih dikatakan "lahan tidur" yang belum dapat dikembangkan dan diolah secara lebih intensif untuk menghasilkan komoditas yang ekonomis. Salah satu kendala serius yang saat ini dihadapi oleh pemilik lahan adalah keterbatasan modal usaha dan tingginya harga harga sarana produksi pertanian. 
P-ISSN 2580 - 7781

E-ISSN 2615 - 3238

Tabel 3. Evaluasi Faktor Penghambat Optimalilasi Penggunaan Lahan Marginal

\begin{tabular}{llccccccc}
\hline No & \multicolumn{1}{c}{ Faktor Penghambat } & BF & ND & NRK & NBD & NBK & TNB & FKK \\
\hline H1 & $\begin{array}{l}\text { Terbatasnya akses terhadap } \\
\text { lembaga keuangan }\end{array}$ & 0.20 & 4 & 2.75 & 0.80 & 0.55 & 1.35 & \\
H2 & $\begin{array}{l}\text { Terbatasnya sarana transportasi } \\
\text { Kurang mendukungnya }\end{array}$ & 0.30 & 4 & 3.58 & 1.20 & 1.08 & 2.28 & \\
H3 & 0.20 & 4 & 3.50 & 0.80 & 0.70 & 1.50 & \\
& $\begin{array}{l}\text { infrastruktur pertanian } \\
\text { H4 }\end{array}$ & & & & & & & \\
Rendanya aplikasi teknologi & 0.30 & 3 & 3.42 & 0.90 & 1.03 & 1.93 & \\
Sepanjang tahun air tidak & 0.20 & 3 & 3.50 & 0.60 & 0.70 & 1.30 & \\
H6 & $\begin{array}{l}\text { Sangat miskin unsur hara dan } \\
\text { rendahnya bahan organik } \\
\text { bahan organik rendah }\end{array}$ & 0.30 & 2 & 3.42 & 0.60 & 1.03 & 1.63 & \\
H7 & & & & & & & \\
& $\begin{array}{l}\text { Banyak lahan yang tidak } \\
\text { digunakan lebih dari 2 tahun }\end{array}$ & 0.40 & 5 & 1.92 & 2.00 & 0.77 & 2.77 & $1^{*}$ \\
\hline
\end{tabular}

*): merupakan prioritas FKK

Keterangan:

BF : Bobot Faktor

ND : Nilai Dukungan

NRK : Nilai Rata-rata Keterkaitan

NBD : Nilai Bobot Dukungan

NBK : Nilai Bobot Keterkaitan

TNB : Total Nilai Bobot

FKK : Faktor Kunci Keberhasilan

Pada Tabel 3 dapat diketahui juga FKK penghambat optimalilasi penggunaan lahan marginal guna mendukung pengembangan komoditas tanaman pangan di Kabupaten Situbondo, yaitu faktor H7 (Banyak lahan tidur) dengan nilai urgensi faktor sebesar 2,77. Potensi sumberdaya lahan di Kabupaten Situbondo merupakan "lahan tidur" yang belum dikembangkan dan diolah secara lebih intensif untuk menghasilkan komoditas yang ekonomis. Salah satu kendala serius yang saat ini dihadapi oleh pemilik lahan adalah keterbatasan modal usaha dan tingginya harga harga sarana produksi pertanian. 


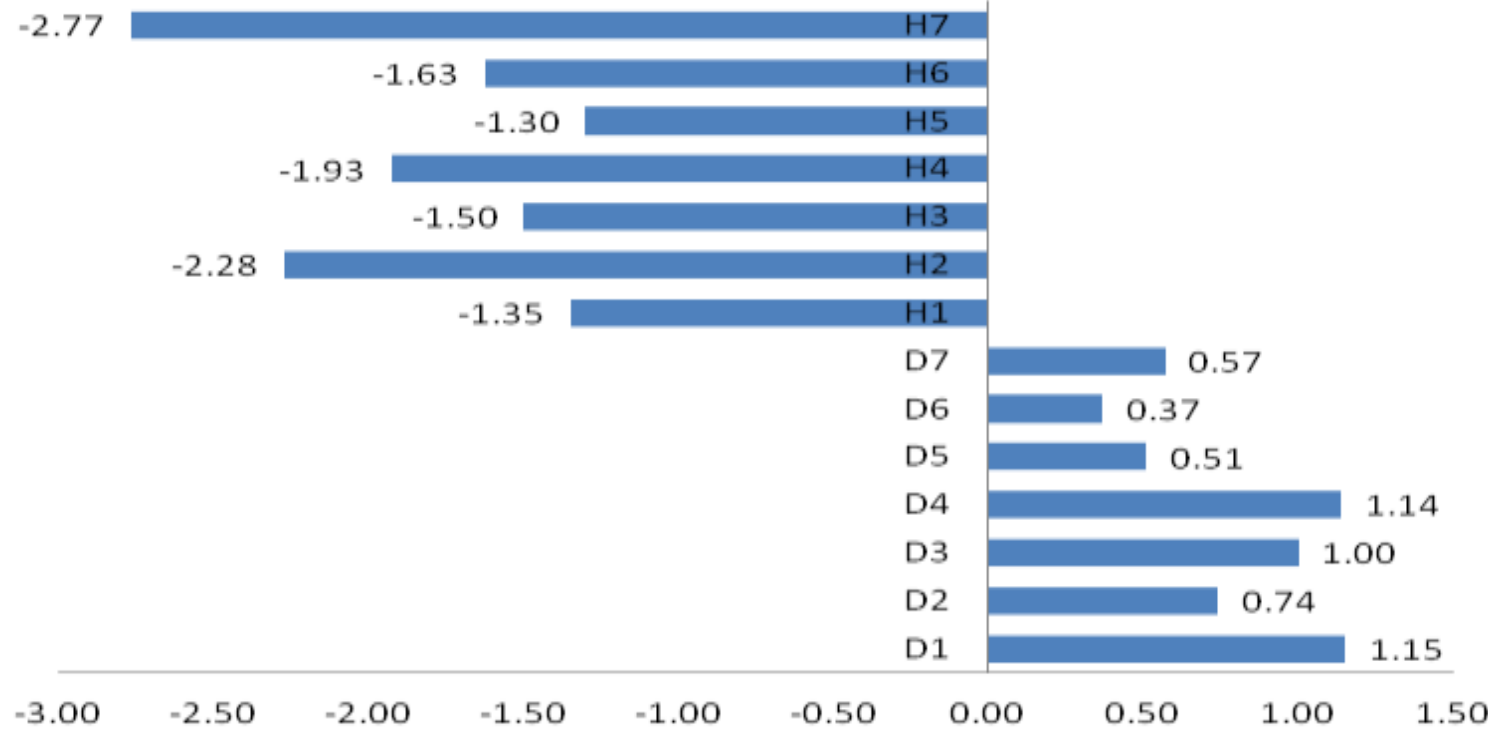

Gambar 1. Medan Kekuatan Optimalilasi Penggunaan Lahan Marginal dalam Pengembangan Komoditas Tanaman Pangan

Setelah diketahui arah optimalilasi penggunaan lahan marginal guna mendukung pengembangan komoditas tanaman pangan di Kabupaten Situbondo selanjutnya merumuskan strategi yang sesuai dengan hasil FKK. Strategi ini merupakan cara yang tepat untuk mencapai tujuan yang telah ditetapkan. Dengan adanya strategi yang sesuai, kegiatan optimalilasi penggunaan lahan marginal guna mendukung pengembangan komoditas tanaman pangan di Kabupaten Situbondo ini nantinya juga tepat sasaran. Berdasarkan hasil analisa FFA, maka strategi yang paling efektif adalah dengan menghilangkan atau meminimalisasi hambatan kunci dan optimalisasi pendorong kunci ke arah tujuan yang akan dicapai. Pendekatan yang demikian ini merupakan pendekatan strategi fokus.

Strategi fokus pada hasil analisa FFA dapat dirumuskan bahwa kekuatan atau pendorong kunci yang telah dipilih difokuskan ke arah tujuan yang telah ditetapkan yaitu untuk optimalilasi penggunaan lahan marginal guna mendukung pengembangan komoditas tanaman pangan di Kabupaten Situbondo. FKK pendorong yang terpilih adalah Tersedianya lahan untuk usahatani, fokus adalah Pengelolaan kesuburan tanah, khususnya penambahan bahan organik, sedangkan untuk FKK penghambat yaitu banyaknya lahan tidur, dengan fokus pengembangan usahatani campuran yang berwawasan korservasi. 
P-ISSN $2580-7781$

E-ISSN 2615 - 3238

Berdasarkan FKK pendorong dan FKK penghambat yang telah dipilih, maka dapat disusun strategi untuk pengembangan optimalisasi penggunaan lahan marginal guna mendukung pengembangan komoditas pangan di Kabupaten Situbondo, yaitu "Pendekatan ekosistem melalui perbaikan kesuburan tanah dan pemilihan berbagai jenis tanaman pangan yang sesuai dan menguntungkan serta usaha peternakan".

\section{KESIMPULAN}

Strategi optimalilasi untuk pengembangan penggunaan lahan marginal guna mendukung pengembangan komoditas tanaman pangan di Kabupaten Siitubondo, yaitu " Pendekatan ekosistem melaui perbaikan kesuburan tanah dan pemilihan berbagai jenis tanaman pangan yang sesuai dan menguntungkan serta usaha peternakan".

\section{DAFTAR PUSTAKA}

BPS Kabupeten Situbondo. 2019. Kabupaten Situbondo Dalam Angka 2019. BPS Kabupeten Situbondo.

Nazir, M. 2013. Metode Penelitian. Ghalia Indonesia, Bogor Soetriono dan Hanafie R. 2017. filsafat ilmu dan metodologi penelitian. Yogyakarta: Andy. 